\title{
Inhalable particulate matter and mitochondrial DNA copy number in highly exposed individuals in Beijing, China: a repeated-measure study
}

Lifang Hou ${ }^{1,2^{*}+}$, Xiao Zhang ${ }^{1 \dagger}$, Laura Dioni ${ }^{3,4}$, Francesco Barretta ${ }^{3,4}$, Chang Dou ${ }^{5}$, Yinan Zheng ${ }^{1}$, Mirjam Hoxha ${ }^{3,4}$, Pier Alberto Bertazzi ${ }^{3,4}$, Joel Schwartz ${ }^{6}$, Shanshan $\mathrm{Wu}^{7}$, Sheng Wang ${ }^{8^{*}}$ and Andrea A Baccarelli ${ }^{6}$

\begin{abstract}
Background: Mitochondria are both a sensitive target and a primary source of oxidative stress, a key pathway of air particulate matter (PM)-associated diseases. Mitochondrial DNA copy number (MtDNAcn) is a marker of mitochondrial damage and malfunctioning. We evaluated whether ambient PM exposure affects MtDNAcn in a highly-exposed population in Beijing, China.

Methods: The Beijing Truck Driver Air Pollution Study was conducted shortly before the 2008 Beijing Olympic Games (June 15-July 27, 2008) and included 60 truck drivers and 60 office workers. Personal PM 2.5 and elemental carbon (EC, a tracer of traffic particles) were measured during work hours using portable monitors. Post-work blood samples were obtained on two different days. Ambient PM 10 was averaged from 27 monitoring stations in Beijing. Blood MtDNAcn was determined by real-time PCR and examined in association with particle levels using mixedeffect models.

Results: In all participants combined, MtDNAcn was negatively associated with personal EC level measured during work hours ( $\beta=-0.059,95 \% \mathrm{Cl}$ : $-0.011 ;-0.0006, p=0.03)$; and 5 -day $(\beta=-0.017,95 \% \mathrm{Cl}$ : $-0.029 ;-0.005, p=0.01)$ and 8-day average ambient $\mathrm{PM}_{10}(\beta=-0.008,95 \% \mathrm{Cl}$ : $-0.043 ;-0.008, \mathrm{p}=0.004)$ after adjusting for possible confounding factors, including study groups. MtDNAcn was also negatively associated among office workers with $E C(\beta=-0.012$, 95\% Cl: -0.022;-0.002, $p=0.02)$ and 8-day average ambient $\mathrm{PM}_{10}(\beta=-0.030,95 \% \mathrm{Cl}$ : $-0.051 ;-0.008, p=0.007)$.

Conclusions: We observed decreased blood MtDNAcn in association with increased exposure to EC during work hours and recent ambient PM 10 exposure. Our results suggest that MtDNAcn may be influenced by particle exposures. Further studies are required to determine the roles of MtDNAcn in the etiology of particle-related diseases.
\end{abstract}

Keywords: China, Mitochondrial DNA, Mitochondrial DNA copy number, Particulate matter, Traffic pollution

\section{Background}

Ambient exposure to particulate matter (PM) has been linked with increased hospitalization and mortality from respiratory and cardiovascular diseases [1]. Short exposures to high levels of PM have been suggested to trigger acute

\footnotetext{
* Correspondence: I-hou@northwestern.edu; shengw@bjmu.edu.cn ${ }^{\dagger}$ Equal contributors

${ }^{1}$ Department of Preventive Medicine Feinberg, School of Medicine Northwestern University, 680 North Lake Shore Drive, Suite 1400, Chicago, IL 60611, USA

${ }^{8}$ Department of Occupational and Environmental, Health Peking University Health Science, Center No. 38 Xueyuan Road Haidian District, Beijing 100191, China Full list of author information is available at the end of the article
}

events, such as acute myocardial infarction and asthma attacks [2,3]. Longer and protracted PM exposures have been shown to increase the risk of chronic diseases such as atherosclerosis, chronic obstructive pulmonary disease, and lung cancer [2,4-6]. In vitro and in vivo studies have found the generation of reactive oxygen species (ROS) and increased oxidative stress as a primary biological process for air pollution-related adverse health effects $[7,8]$.

Mitochondria are the major intracellular source and primary target of ROS. Each human cell contains between several hundred and over a thousand mitochondria, each carrying 2-10 copies of mitochondrial DNA (MtDNA).

\section{() Biomed Central}

(c) 2013 Hou et al.; licensee BioMed Central Ltd. This is an Open Access article distributed under the terms of the Creative Commons Attribution License (http://creativecommons.org/licenses/by/2.0), which permits unrestricted use, distribution, and reproduction in any medium, provided the original work is properly cited. 
MtDNA copy number (MtDNAcn) is correlated with the size and number of mitochondria, which have been shown to change under different energy demands, as well as different physiological or environmental conditions [9]. Decreased blood MtDNA content has been associated with various diseases or conditions, such as diabetes and insulin resistance [10-13], glucose dysregulation [14], cognitive function [15], osteoporosis [16-18], renal cell carcinoma [19], and hypertension [12,20]. Evidence on environmental exposure and MtDNAcn has begun to accumulate, showing increased blood MtDNAcn in relation to exposure to benzene [21,22] and ambient PM [23], decreased blood MtDNAcn in relation to smoking [24], and decreased placenta MtDNAcn in relation to prenatal exposure to $\mathrm{PM}_{10}$ [25] and maternal smoking [26]. These findings suggest that mitochondrial damage and dysfunction, as reflected in MtDNAcn, may represent a biological effect along the path linking PM inhalation to its health effects.

Beijing, China, has some of the highest levels of air pollution in the world [27]. Traffic-derived air pollution is critical in Beijing due to its very high population density, rapid increase in vehicular traffic, and limited emission control. Investigating individuals exposed to high levels of PM, such as those in Beijing, may help identify MtDNAcn changes that cannot be easily identified in populations with lower exposures. In the present study, we measured blood MtDNAcn in truck drivers and indoor office workers in Beijing to investigate the association of blood MtDNAcn with exposure to PM.

\section{Material and methods}

\section{Study population and design}

The Beijing Truck Driver Air Pollution Study (BTDAS), conducted between June 15 and July 27, 2008, included 60 truck drivers and 60 indoor office workers. All study participants worked and lived in the Beijing metropolitan area and had been on their current jobs for at least two years. No subject was on regular medication, including anti-inflammatory drugs or aspirin during the course of the study. Because PM levels are highly variable on a day-to-day basis, we examined all participants on two work days separated by 1-2 week periods. Truck drivers and indoor office workers were matched by sex, smoking, and education, and partially matched (5-year intervals) by age. In-person interviews using a detailed questionnaire were conducted to collect information on demographics, lifestyle, and other exposures. Information on time-varying factors, including tea, alcohol, and smoking, was obtained for past usual exposure, as well as on each examination day. Individual written informed consent was obtained from all participants prior to enrollment in the study. Institutional Review Board approval at all participating institutions was obtained prior to study participant recruitment.

\section{Personal $\mathrm{PM}_{2.5}$ exposure measurements}

We measured average personal $\mathrm{PM}_{2.5}$ on both examination days using gravimetric samplers worn by the study participants during the 8 hours of work. The air sampler was carried in a belt pack with the inlet clipped near the breathing zone. Each air sampler setup included an Apex pump (Casella Inc., Bedford, UK), a Triplex Sharp-Cut Cyclone (BGI Inc., Waltham, Massachusetts, USA), and a 37-mm Teflon filter placed on top of a drain disc and inside a metal filter holder. The filters were kept under atmosphere-controlled conditions before and after sampling and were weighed with a microbalance (MettlerToledo Inc., Columbus, Ohio, USA). A time-weighted average of $\mathrm{PM}_{2.5}$ concentration was recorded by dividing the change in filter weight before and after the sampling by the volume of air sampled. We found high reproducibility of $\mathrm{PM}_{2.5}$ measures $(\mathrm{r}=0.944)$ in replicate measures on a subset of 24 participants who wore two monitors at the same time (see Additional file 1: Figure S1). The blackness of the same filters used to measure $\mathrm{PM}_{2.5}$ was assessed using an EEL Model M43D Smokestain Reflectometer, applying the standard black-smoke index calculations of the absorption coefficients based on reflectance [28]. We assumed a factor of 1.0 for converting the absorption coefficient to elemental carbon (EC) mass [29,30], which was then divided by the sampled air volume to calculate average EC exposure concentration [28]. EC is a combustion by-product contained in PM that has been used as a surrogate measure for PM from gasoline- and especially dieselpowered motor vehicles [29].

\section{Ambient $\mathrm{PM}_{10}$ data}

Ambient $\mathrm{PM}_{10}$ data during the study period were obtained from the Beijing Municipal Environmental Bureau (http://www.bjepb.gov.cn/air2008/Air.aspx). We used daily averages of $\mathrm{PM}_{10}$ levels computed from data obtained from 27 monitoring stations to estimate the average $\mathrm{PM}_{10}$ level in Beijing. The locations of the 27 monitoring stations were distributed across the Beijing city area to generate an average representative of the entire city. We used the ambient $\mathrm{PM}_{10}$ data as an indicator of exposure in the days immediately before the examination days, and used multiple averaging time windows, which included 1-day mean (24-hour average of the examination day), 2-day mean (average of the examination day and 1 day before the examination), 5-day mean (average of the examination day and 4 days before the examination), and 8-day mean (average of the examination day and 7 days before the examination).

\section{Analysis of Relative MtDNAcn}

All samples were processed, collected, and analyzed using standardized protocols. We used EDTA tubes to collect 7 
$\mathrm{ml}$ of whole blood that was promptly centrifuged at 2500 rpm for 15 minutes. Total DNA was extracted from $200 \mu \mathrm{l}$ buffy coat, using the Wizard Genomic DNA purification kit (Promega, Madison, WI). MtDNAcn was measured by a quantitative real-time polymerase chain reaction (qPCR) assay, as previously described [19,31]. The assay measures MtDNAcn in experimental samples compared to a standard DNA sample used as reference in all the reactions. A relative value equal to 1 indicates that the experimental sample analyzed has MtDNAcn equal to that of the standard reference DNA sample used in the analysis. The assay is based on determinations of the ratio of mitochondrial (Mt) copy number to single copy gene (human [beta] globin: hbg) copy number, which is measured on both the experimental samples and the standard reference DNA. The Mt PCR mix was: iTaq ${ }^{\text {TM }}$ SYBR $^{\oplus}$ Green Supermix with ROX (Bio-Rad) 1x, MtF3212 500 nM (primer), MtR3319 500 nM, EDTA 1x. The hbg PCR mix was: iTaq SYBR Green Supermix (Bio-Rad) 1x, hbgF 500 nM (primer), hbgR 500 nM, EDTA 1x. 4 ng DNA was loaded in a $10 \mu \mathrm{l}$ PCR reaction. We used MtDNA and hbg primers as previously described [23,32]. For the reference DNA, we used pooled DNA from 20 participants randomly selected from our study participants (500 ng for each sample) to generate in every Mt and S PCR run a fresh standard curve, which ranged from $20 \mathrm{ng} / \mu \mathrm{l}$ to $0.25 \mathrm{ng} / \mu \mathrm{l}$. The mean slopes of standard curve for $\mathrm{Mt}$ and $\mathrm{S}$ were -3.51 and -3.42 respectively, and the $\mathrm{R}^{2}$ for each standard curve was 0.99 or greater. Standard deviations for the cycle of threshold (Ct) value were accepted at 0.25. Otherwise, the test was repeated. All PCRs were performed on the 7900 Fast RealTime PCR System (Applied Biosystems, Foster City, CA). The thermal cycling conditions for the MtDNA PCR were 2 minutes at $50^{\circ} \mathrm{C}$ and 3 minutes at $95^{\circ} \mathrm{C}$ to activate the hot-start iTaq DNA polymerase, followed by 35 cycles comprised of $15 \mathrm{~s}$ denaturation at $95^{\circ} \mathrm{C}$ and $60 \mathrm{~s}$ anneal/ extend at $60^{\circ} \mathrm{C}$. The thermal cycling conditions for the hbg PCR were 3 minutes at $95^{\circ} \mathrm{C}$ to activate the hot-start iTaq DNA polymerase, followed by 35 cycles comprised of $15 \mathrm{~s}$ denaturation at $95^{\circ} \mathrm{C}$ and $60 \mathrm{~s}$ anneal/extend at $58^{\circ} \mathrm{C}$. Each run was completed by melting curve analysis to confirm the amplification specificity and absence of primer dimers. All the laboratory personnel performing the experiments described above were blinded to the exposure status of the DNA samples.

All samples were randomized in each PCR plate, and the samples obtained on two different days of each subject were kept on the same plate. All samples were run in triplicates in 384-well plates. The average of the three Mt measurements was divided by the average of the three $\mathrm{S}$ measurements to calculate the $\mathrm{Mt} / \mathrm{S}$ ratio for each sample. The coefficient of variation for the $\mathrm{Mt} / \mathrm{S}$ ratio in duplicate samples analyzed on two different days was $8 \%$.

\section{Statistical analysis}

Standard descriptive statistics were used to present the characteristics of truck drivers and office workers. Differences in participant characteristics between the two groups were tested using Student's t-tests and Fisher's exact tests. Because MtDNAcn was measured twice for each participant on two work days separated by 1-2 week periods, we used mixed-effects models to regress MtDNAcn over the occupational group ( 0 , office workers; 1 , truck drivers) and test for differences between groups and estimate groupspecific means and standard deviations (SDs). We fitted unadjusted models, as well as models adjusted for variables either matched or not completely matched between the two groups, i.e. sex (male, female), smoking (never, defined as those who have never smoked a cigarette or who smoked fewer than 100 cigarettes in their entire lifetime; former, defined as those who have smoked at least 100 cigarettes in their lifetime, but currently do not smoke; and current, defined as those who were currently smoking), age (continuous), body mass index (BMI) (continuous), work hours per week (continuous), and pack-year of cigarette smoking (continuous). For analyses on all participants, we further adjusted for study groups (truck drivers vs. office workers). The mixed-effect regression models were:

$$
Y=\beta_{0}+\beta_{1}(\text { Group })+\beta_{2} X_{2}+\ldots+\beta_{n} X_{n}+\xi+e
$$

where $\beta_{0}$ is the overall intercept; $\beta_{1}$ is the regression coefficient for the group; $\beta_{2} \ldots \beta_{n}$ are the regression coefficients for the covariates included in multivariate models; $\xi$ is the random effect for the participant, and $e$ is the residual error term.

We also evaluated the associations of personal $\mathrm{PM}_{2.5}$, EC, and ambient $\mathrm{PM}_{10}$ (1-day, 2-day, 5-day, or 8-day means) with MtDNAcn using mixed-effects models adjusted for group, age, sex, BMI, smoking status, pack-years of cigarette smoking, and work hours per week. To optimize power, we conducted primary analyses on the association of exposure measures and MtDNAcn by fitting these models to all participants combined. Secondarily, we evaluated associations in office workers or truck drivers separately. The mixed-effects models were:

$$
Y=\beta_{0}+\beta_{1}(\operatorname{Exp})+\beta_{2} X_{2}+\ldots+\beta_{n} X_{n}+\xi+e
$$

where $\beta_{0}$ is the overall intercept; $\beta_{1}$ is the regression coefficient for the exposure variable $\left(\mathrm{PM}_{2.5}, \mathrm{EC}\right.$, or $\left.\mathrm{PM}_{10}\right) ; \beta_{2}$. . . $\beta_{n}$ are the regression coefficients for the covariates included in multivariate models; $\xi$ is the random effect for the participant, and $e$ is the residual error term. All tests were 2 -sided and an alpha level $<0.05$ was considered significant. All analyses were performed in SAS 9.2 (SAS Institute Inc., Cary, NC). 


\section{Results}

Table 1 shows the characteristics of the 60 office workers and 60 truck drivers. Truck drivers were moderately but significantly older than office workers. Truck drivers had higher BMI and reported a higher number of pack-years of smoking and longer work hours per week during the study period.

As shown in Table 2, average personal $\mathrm{PM}_{2.5}$ was 126.8 $\mu \mathrm{g} / \mathrm{m}^{3}\left(\mathrm{SD}=68.8 \mu \mathrm{g} / \mathrm{m}^{3}\right)$ in truck drivers and $94.6 \mu \mathrm{g} / \mathrm{m}^{3}$ $\left(\mathrm{SD}=64.9 \mu \mathrm{g} / \mathrm{m}^{3}\right)$ for office workers $(\mathrm{p}<0.001)$. Average personal EC was $17.2 \mu \mathrm{g} / \mathrm{m}^{3}\left(\mathrm{SD}=6.6 \mu \mathrm{g} / \mathrm{m}^{3}\right)$ in truck drivers and $13.0 \mu \mathrm{g} / \mathrm{m}^{3}\left(\mathrm{SD}=4.0 \mu \mathrm{g} / \mathrm{m}^{3}\right)$ for office workers $(\mathrm{p}<0.001)$. As expected, the levels of ambient $\mathrm{PM}_{10}$ in the city of Beijing on the days before the examinations (1-8 day means) did not differ between truck drivers and office workers.

In unadjusted analyses, mean MtDNAcn was 1.04 $(\mathrm{SD}=0.22)$ in truck drivers and $1.05(\mathrm{SD}=0.22)$ in office workers $(\mathrm{p}=0.73)$. In multiple regression models adjusted for sex, age, BMI, smoking status, work-hour week, and pack-years of smoking, the estimated mean MtDNAcn did not differ between truck drivers $(1.05, \mathrm{SD}=0.24)$ and office workers (1.09, SD=0.25) $(\mathrm{p}=0.40)$ (Table 3). Our further analysis on measurement of MtDNAcn on each work day by study groups resulted in comparable results (data not shown). We also compared the MtDNAcn between males and females, finding that the mean MtDNAcn is significantly higher in females $(1.14, \mathrm{SD}=0.59)$ than in males $(0.98, \mathrm{SD}=0.25) \quad(\mathrm{p}=0.002)$ in multiple regression model (see Additional file 1: Table S1).

Table 4 shows the associations of MtDNAcn with the levels of personal $\mathrm{PM}_{2.5}$, EC, and ambient $\mathrm{PM}_{10}$. Personal $\mathrm{PM}_{2.5}$ measured during work hours did not show any significant association with MtDNAcn in all participants combined, office workers, or truck drivers. In all participants combined, MtDNAcn decreased in association with higher EC measured during work hours $(\beta=-0.059,95 \%$ CI: $-0.011 ;-0.0006, \mathrm{p}=0.03)$. In office workers, MtDNAcn was also negatively associated with EC measured during work hours ( $\beta=-0.012,95 \% \mathrm{CI}$ : $-0.022 ;-0.002, \mathrm{p}=0.02)$, whereas in truck drivers the negative effect was smaller and not significant. In all participants combined, MtDNAcn decreased in association with increased levels of 5-day and 8-day means of ambient $\mathrm{PM}_{10}$. Each $10 \mu \mathrm{g} / \mathrm{m}^{3}$ increase in the 5-day mean of ambient $\mathrm{PM}_{10}$ was associated with an average decrease of 0.017 relative units in MtDNAcn (95\% CI: $-0.029 ;-0.005, \mathrm{p}=0.01$ ) in the analyses on all study participants. Each $10 \mu \mathrm{g} / \mathrm{m}^{3}$ increase in the 8-day mean of

Table 1 Characteristics of the study participants

\begin{tabular}{|c|c|c|c|}
\hline & $\begin{array}{l}\text { Office workers } \\
(n=60)\end{array}$ & $\begin{array}{l}\text { Truck drivers } \\
(n=60)\end{array}$ & $p$-value ${ }^{a}$ \\
\hline Age [years], mean \pm SD & $30.27 \pm 7.96$ & $33.53 \pm 5.65$ & 0.01 \\
\hline \multicolumn{4}{|l|}{ Sex, n (\%) } \\
\hline Male & $40(66.67)$ & $40(66.67)$ & \\
\hline Female & $20(33.33)$ & $20(33.33)$ & 1.00 \\
\hline BMI $\left[\mathrm{kg} / \mathrm{m}^{2}\right]$, mean \pm SD & $22.76 \pm 3.38$ & $24.27 \pm 3.21$ & 0.01 \\
\hline \multicolumn{4}{|l|}{ Smoking, n (\%) } \\
\hline Never smoker & $35(58.33)$ & $34(56.67)$ & \\
\hline Former & $2(3.33)$ & $2(3.33)$ & \\
\hline Current & $23(38.33)$ & $24(40)$ & 1.00 \\
\hline Pack-years of smoking, mean $\pm \mathrm{SD}^{\mathbf{b}}$ & $1.2 \pm 2.7$ & $5.1 \pm 9.3$ & 0.003 \\
\hline Work hours per week, mean \pm SD & $50.6 \pm 11.0$ & $67.3 \pm 14.0$ & $<0.001$ \\
\hline \multicolumn{4}{|l|}{ Day of the week on the two study days, $n(\%)$} \\
\hline Monday & $16(13.33)$ & $19(15.83)$ & \\
\hline Tuesday & $18(15)$ & $13(10.83)$ & \\
\hline Wednesday & $14(11.67)$ & $15(12.5)$ & \\
\hline Thursday & $15(12.5)$ & $20(16.67)$ & \\
\hline Friday & $17(14.17)$ & $19(15.83)$ & \\
\hline Saturday & $18(15)$ & $16(13.33)$ & \\
\hline Sunday & $22(18.33)$ & $18(15)$ & $0.88^{c}$ \\
\hline Average temperature on the two study days, mean \pm SD & $25.36 \pm 2.51$ & $25.34 \pm 2.51$ & $0.96^{c}$ \\
\hline Average dew point on the two study days, mean \pm SD & $20.63 \pm 2.06$ & $20.61 \pm 2.13$ & $0.93^{c}$ \\
\hline
\end{tabular}


Table 2 Levels of personal exposure to $\mathrm{PM}_{2.5}$ and Elemental Carbon (EC) during work hours, and of ambient $\mathrm{PM}_{10}$ on and before the examination days

\begin{tabular}{|c|c|c|c|c|c|c|c|c|c|c|c|c|c|c|c|c|c|}
\hline \multirow[t]{2}{*}{ Time window } & \multicolumn{8}{|c|}{ Office workers } & \multicolumn{9}{|c|}{ Truck drivers } \\
\hline & $\mathrm{N}$ & Mean & SD & 10pct & $25 p c t$ & Median & $75 p c t$ & 90 pct & $\mathbf{N}$ & Mean & SD & $10 p c t$ & $25 p c t$ & Median & $75 p c t$ & $90 p c t$ & $p$-value \\
\hline \multicolumn{18}{|c|}{ Personal $\mathrm{PM}_{2.5}\left(\mu \mathrm{g} / \mathrm{m}^{3}\right)$ on the examination days, from personal monitors ${ }^{\mathrm{a}}$} \\
\hline 8 hours & 120 & 94.6 & 64.9 & 22.4 & 48.5 & 86.2 & 126.6 & 183.4 & 119 & 126.8 & 68.8 & 46.3 & 73.9 & 116.8 & 160.5 & 213.9 & $<0.001$ \\
\hline \multicolumn{18}{|c|}{ Personal EC $\left(\mu \mathrm{g} / \mathrm{m}^{3}\right)$ on the examination days, from personal monitors ${ }^{a}$} \\
\hline 8 hours & 118 & 13.0 & 4.0 & 7.1 & 10.0 & 13.2 & 15.8 & 18.4 & 120 & 17.2 & 6.6 & 9.2 & 12.9 & 16.7 & 20.9 & 26.1 & $<0.001$ \\
\hline \multicolumn{18}{|c|}{ Ambient $\mathrm{PM}_{10}\left(\mu \mathrm{g} / \mathrm{m}^{3}\right)$ from ambient monitors on the days prior to the examination days } \\
\hline 1-day mean & 120 & 121.5 & 47.8 & 72.0 & 82.0 & 118.0 & 146.0 & 186.0 & 120 & 119.5 & 51.2 & 64.0 & 82.0 & 118.0 & 142.0 & 188.0 & 0.76 \\
\hline 2-day mean & 120 & 121.6 & 38.0 & 74.5 & 93.0 & 125.0 & 146.0 & 173.0 & 120 & 119.3 & 40.3 & 66.0 & 91.0 & 120.0 & 144.0 & 157.0 & 0.64 \\
\hline 5-day mean & 120 & 119.5 & 26.9 & 80.7 & 105.6 & 119.6 & 138.0 & 148.8 & 120 & 118.2 & 25.6 & 81.0 & 96.8 & 119.6 & 136.8 & 144.0 & 0.69 \\
\hline 8-day mean & 120 & 119.5 & 23.0 & 84.9 & 101.8 & 119.9 & 141.5 & 146.5 & 120 & 120.2 & 21.5 & 95.6 & 102.8 & 120.4 & 139.0 & 146.3 & 0.81 \\
\hline
\end{tabular}

ambient $\mathrm{PM}_{10}$ was associated with an average decrease of 0.008 relative units in MtDNAcn (95\% CI: -0.043; -0.008, $\mathrm{p}=0.004$ ) in the analyses on all study participants. Stratified analyses in office workers and truck drivers showed the associations of the 5- and 8-day means of ambient $\mathrm{PM}_{10}$ with MtDNAcn in each of the two groups, although it was statistically significant only in office workers for the 8-day mean of ambient $\mathrm{PM}_{10}$ ( $\beta=-0.030,95 \%$ CI: $-0.051 ;-0.008, p=0.007$ ) (Table 4). Our stratified analysis by sex showed that the effect of exposure, including personal EC and $\mathrm{PM}_{10}$ (2-day, 5-day, and 8-day means), on MtDNAcn was stronger in men than in women (see Additional file 1: Table S2).

We previously examined the effects of PM exposure on blood pressure (BP) in this study population, finding a delayed effect of ambient $\mathrm{PM}_{10}$ on $\mathrm{BP}$ [33]. In this study, we examined the correlations of MtDNAcn with $\mathrm{BP}$ and other risk factors. We observed an inverse association of MtDNAcn with systolic $(\mathrm{p}=0.002)$ and diastolic BP $(\mathrm{p}<0.001)$, as well as with BMI $(\mathrm{p}=0.049)$ and pack-years of smoking $(\mathrm{p}=0.038)$ (see Additional file 1: Table S3).

\section{Discussion}

The present study showed lower MtDNAcn in association with increased levels of personal EC measured during work hours and of ambient $\mathrm{PM}_{10}$ averaged over 5 and 8 days before the MtDNAcn examination days. We

Table 3 Mean mitochondrial DNA copy number (MtDNAcn) in truck drivers and office workers

\begin{tabular}{lccc}
\hline & $\begin{array}{c}\text { Office workers } \\
\text { (obs=120) }\end{array}$ & $\begin{array}{c}\text { Truck drivers } \\
\text { (obs=120) }\end{array}$ & p-value \\
\hline Mean \pm SD & Mean \pm SD & \\
Unadjusted & $1.05 \pm 0.22$ & $1.04 \pm 0.22$ & 0.73 \\
Adjusted $^{\mathrm{a}}$ & $1.09 \pm 0.25$ & $1.05 \pm 0.24$ & 0.40 \\
\hline
\end{tabular}

a Adjusted for age, sex, BMI, pack-years, smoking status (never, former, current), and work hours per week. found no significant associations of MtDNAcn with personal measures of $\mathrm{PM}_{2.5}$ taken during work hours on the day of the examination, nor with $\mathrm{PM}_{10}$ on the examination day and the 2-day mean. MtDNAcn was similar in truck drivers and office workers. Thus our results do not support effects of work-related long-term differences in exposure to air particles.

Research on MtDNAcn in relation to air pollution is still limited with inconsistent results. Two studies have demonstrated that individuals exposed to higher ambient benzene exhibited higher MtDNAcn than participants with lower exposure [21,22]. In our previous study of healthy steel workers in Northern Italy, personal $\mathrm{PM}_{10}$ and $\mathrm{PM}_{1}$ were associated with increased MtDNAcn [23]. In this group of Italian steel foundry workers with high exposure to metal-rich PM, MtDNAcn was determined from blood DNA obtained on the $1^{\text {st }}$ and $4^{\text {th }}$ day of the same work week after two off-work days [23]. Exposures to $\mathrm{PM}_{10}, \mathrm{PM}_{1}$, and coarse particles showed a doseresponse relationship with increased MtDNAcn on both the $1^{\text {st }}$ and $4^{\text {th }}$ days of the study week, indicating that the correlations between PM exposure and MtDNAcn were the result of a more protracted exposure to PM, rather than of the acute exposure between the two days. In the present study, we observed significant negative association of 5- and 8-day means of ambient $\mathrm{PM}_{10}$ with MtDNAcn in office workers, but not in truck drivers. It should be noted that the dose-response slope between particles and cardiovascular mortality has been shown to be nonlinear, with lower slopes at higher particle concentrations [34]. Therefore, PM effects might be substantial at low- to middle-range doses and taper off at higher concentrations. Also, these results suggest that MtDNA may react differently under the influence of different environmental factors, leading to differences in copy numbers. Compared with the present study, higher $\mathrm{PM}_{10}$ level $\left(\right.$ median $\left.=179.44 \mu \mathrm{g} / \mathrm{m}^{3}\right)$, metal components (i.e., chromium, lead, arsenic, nickel, manganese), older 
Table 4 Effect of ambient particles on mitochondrial DNA copy number ${ }^{a}$ at the end of the work shift, by group and on all subjects

\begin{tabular}{|c|c|c|c|c|c|c|c|c|c|}
\hline & \multicolumn{3}{|c|}{ All subjects (obs $=240)^{b, c}$} & \multicolumn{3}{|c|}{ Office workers (obs=120) } & \multicolumn{3}{|c|}{ Truck drivers (obs $=120)^{d}$} \\
\hline & $\beta$ & $(95 \% \mathrm{Cl})$ & $\overline{p \text {-value }}$ & $\beta$ & $(95 \% \mathrm{Cl})$ & p-value & $\beta$ & $(95 \% \mathrm{Cl})$ & p-value \\
\hline \multicolumn{10}{|c|}{ Mitochondrial DNA Copy Number (\%) } \\
\hline Personal PM 2.5 (work hours) & 0.001 & $(-0.003 ; 0.006)$ & 0.55 & 0.001 & $(-0.006 ; 0.007)$ & 0.81 & 0.005 & $(-0.002 ; 0.012)$ & 0.18 \\
\hline Personal EC (work hours) & -0.059 & $(-0.011 ;-0.006)$ & 0.03 & -0.012 & $(-0.022 ;-0.002)$ & 0.02 & -0.004 & $(-0.010 ; 0.003)$ & 0.28 \\
\hline Ambient $\mathrm{PM}_{10}$ (1-day mean) & -0.005 & $(-0.011 ; 0.002)$ & 0.18 & -0.004 & $(-0.012 ; 0.004)$ & 0.28 & -0.003 & $(-0.011 ; 0.004)$ & 0.40 \\
\hline Ambient $\mathrm{PM}_{10}$ (2-day mean) & -0.006 & $(-0.014 ; 0.002)$ & 0.12 & -0.006 & $(-0.012 ; 0.003)$ & 0.19 & -0.002 & $(-0.012 ; 0.008)$ & 0.67 \\
\hline Ambient $\mathrm{PM}_{10}$ (5-day mean) & -0.017 & $(-0.029 ;-0.005)$ & 0.01 & -0.011 & $(-0.025 ; 0.004)$ & 0.15 & -0.012 & $(-0.028 ; 0.004)$ & 0.14 \\
\hline Ambient $\mathrm{PM}_{10}$ (8-day mean) & -0.008 & $(-0.043 ;-0.008)$ & 0.004 & -0.030 & $(-0.051 ;-0.008)$ & 0.007 & -0.012 & $(-0.036 ; 0.013)$ & 0.35 \\
\hline
\end{tabular}

${ }^{a}$ Adjusted for age, sex, BMI, smoking status (never, former, current), pack-years of smoking, and work hours per week.

${ }^{b}$ Adjusted for group, age, sex, BMl, smoking status (never, former, current), pack-years of smoking, and work hours per week.

c For $\mathrm{PM}_{2.5}$ exposure, statistics are estimated on 239 observations because of a missing value in truck drivers group in work day 2.

${ }^{\mathrm{d}}$ For $\mathrm{PM}_{2.5}$ exposure, statistics are estimated on 119 observations because of a missing value in work day 2 .

age (mean $=44$ years), and different race in steel foundry workers might have all contributed to the discrepancy in the results between the two studies. In the present study, levels of EC during the work hours, taken as a tracer of exposure to traffic particles, were associated with decreased MtDNAcn. This finding indicated effects on MtDNAcn from traffic particles that appeared on the same day of the study. The finding of stronger effects of EC in office workers than that in truck drivers suggests that the decrease in MtDNAcn did not result from the effects of work-related exposure to traffic air particles. Compared to truck drivers, the office workers may represent a more homogenous group in relation to different variables, such as socioeconomic status, smoking, and other factors that may have the potential to influence MtDNAcn. Also, unmeasured exposures or differences in particle content may have influenced MtDNAcn more in office workers than in truck drivers. However, we conducted a test for interaction to determine whether the effects of air particle exposures on MtDNAcn in office workers were different from those in truck drivers. We did not observe any significant interaction $(p>0.05)$ (data not shown), indicating no significant difference in the slope of the relation between air particle exposures and MtDNAcn between office workers and truck drivers. Therefore, the observed stronger association and larger effect in office workers than truck drivers may mostly reflect imprecision in the regression estimates due to limited sample size. Larger studies are warranted in larger groups with different sources of exposure.

MtDNAcn is dependent on oxidative stress level, cell antioxidant capacity, and quality of mitochondria and MtDNA [35]. Mild oxidative stress may stimulate MtDNAcn synthesis, while high exposure may result in decreased or no synthesis, owing to severe oxidative damage of cells. PM exposure, particularly from traffic sources, induces systemic inflammation [36], which may lead to decreased MtDNAcn. Haden et al. found that MtDNAcn was reduced in the early phase of sepsis as a consequence of the sepsis-induced oxidative damage and inflammation in mice [37]. Pyle et al. observed decreased MtDNAcn in the blood of sepsis patients compared with controls [38].

MtDNA is dynamic and can be influenced by multiple factors. We observed inverse associations of MtDNAcn with factors that can cause oxidative stress, including cigarette smoking and BMI (see Additional file 1: Table S3). The observed negative association of MtDNAcn with pack-years of smoking is consistent with previous findings that have associated pack-years of smoking with lower blood MtDNAcn in men [24]. We also found a negative association of BMI with MtDNAcn. A strong inverse association was reported between BMI and MtDNAcn in adipocytes in healthy subjects [39]. In this study population, we have previously reported an association of increased $\mathrm{BP}$ with ambient $\mathrm{PM}_{10}$ over 5 or 8 days before the examination days [33]. In the present analysis, we observed decreased MtDNAcn with increasing systolic and diastolic BP (see Additional file 1: Table S3). This finding is in line with previous studies showing a negative correlation between MtDNAcn in blood and BP [12,20]. Also, previous investigations have associated decreased blood MtDNAcn with PM-related diseases, such as cognitive function [15]. Decreased MtDNAcn in placental tissues has been associated with prenatal $\mathrm{PM}_{10}$ exposure (mean=22.7 \pm 3.7 in whole pregnancy) [25] and maternal smoking [26].

Our additional analysis on male and female have found higher mtDNAcn in women than that in men, which is consistent with two previous studies [40,41]. Thyagarajan et al. found that individuals with high dietary intake of $\alpha$ - and $\beta$-carotenes had slightly higher MtDNAcn, and suggested that lifestyle factors may contribute to the gender-related difference [40]. However, the exact mechanisms underlying the sex-related differences are not well understood. Further, in our stratified analysis on the effect of exposures by sex, we found that the effect of exposure, including personal EC and $\mathrm{PM}_{10}$ (2-day, 5-day, and 8-day 
means), on MtDNAcn appears to be stronger in men than in women. Similary, Purdue et al. has reported a stronger association of MtDNAcn with renal cell carcinoma in men than women [41]. However, due to the limited sample size, particularly, in the female group, our results need to be interpreted with caution. Larger studies are needed to examine sex-differences in susceptibility toward air pollution in the future.

Some previous investigations have suggested that MtDNA has a long-half life and low turnover rates. For instance, Collins et al. showed a half-life of approximately 350 days for MtDNA in rats [42]. However, other studies have shown more rapid half-lives, varying between 7 and 31 days [43]. It has been postulated that the MtDNA turnover rates are variable depending on the tissue investigated as well as the effects of environmental factors [44]. Our data indicate that relatively rapid changes in MtDNAcn may occur in a cell type with high turnover rates, such as neutrophils with an average half-life of 5-6 days [45], at high levels of exposure to air particles.

Our study had the advantage of having both personal and ambient measures of air pollution. Our technical validation of personal $\mathrm{PM}_{2.5}$ measures showed high reproducibility $(r=0.944)$. We also recognize that our study is subject to a number of limitations. In our investigation, we did not examine inflammatory markers, which may play important roles in both mtDNAcn changes and PM-related diseases, thus limiting our ability of understanding how inflammation may affect PM-related MtDNAcn changes. Further studies are needed to examine cytokines, in particular, IL2, IL4, IL6, IL8, and TNF $\alpha$ that have been previously associated with $\mathrm{PM}$ exposure [46-48], and high-sensitivity C-reactive protein (hs-CRP) [49] to clarify the role of inflammation in the relation of MtDNAcn with PM exposure. Because of the relatively small sample size, we cannot exclude false negative or chance findings. In addition to using personal $\mathrm{PM}_{2.5}$ measures, we used stationary measures of ambient $\mathrm{PM}_{10}$ to represent exposures, which are just a proxy of personal exposure. However, simulation studies have shown that the error introduced by using data from stationary monitors is highly unlikely to bias away from the null, and indicated that this exposure misclassification may lead to an underestimation of the health effects of air pollution [50]. In addition, serial measures of ambient particulate concentrations have been shown to be representative of variations in personal exposures [51], particularly in the presence of high ambient PM levels [52]. The observed decreased MtDNAcn in our study suggests that high doses of exposures, such as those found in Beijing, might lead to clearance of cells with highly damaged mitochondria. However, the clinical significance of such small changes in MtDNA content remains largely unknown. More studies are warrented to examine the risk of future disease in large cohorts with clinical disease outcomes.

Overall, our investigation provided evidence that shortterm exposure to air pollution is associated with decreased MtDNAcn. These findings suggest that damaged mitochondrial DNA, as reflected in peripheral blood MtDNAcn, may reflect recent toxic exposures and potentially contribute to the etiology of PM-related diseases. Further studies are required to validate the present findings, as well as to better elucidate the time relationships between PM exposure and MtDNAcn.

\section{Additional file}

Additional file 1: Figure S1. Measures of $\mathrm{PM}_{2.5}$ from two independent personal monitors worn at the same time by a subset of 12 study subjects to test the accuracy of the measurements. Table S1. Pearson's Correlation Coefficient between MtDNAcn and risk factors. Table S2. Pearson's correlation coefficient among mtDNAcn, age, smoking, BMI and blood pressure. Table S3. Correlation between MtDNAcn and risk factors in bivariate regressions model. Table S4. Correlation between MtDNAcn and risk factors in multiple regression model.

\section{Abbreviations}

BMl: Body mass index; BP: Blood pressure; BTDAS: Beijing Truck Driver Air Pollution Study; Cl: Confidence interval; EC: Elemental carbon; MtDNA: Mitochondrial DNA; MtDNAcn: MtDNA copy number; qPCR: Quantitative real-time polymerase chain reaction; PM: Particulate matter; $\mathrm{PM}_{2.5}$ : Particulate matter $\leq 2.5 \mu \mathrm{m}$; $\mathrm{PM}_{10}$ : Particulate matter $\leq 10 \mu \mathrm{m}$; ROS: Reactive oxygen species; SD: Standard deviation.

\section{Competing interests}

The authors declare that they have no competing interests.

\section{Authors' contributions}

Hou, Schwartz, Wang, and Baccarelli generated the study concept, conducted studies and supervised laboratory assays, data analysis and interpretation, participated in manuscript writing. Hou and Zhang contributed to data interpretation and manuscript writing. Hoxha and Dioni performed the laboratory analyses. Wang, Dou, and Wu were involved in study conduction. Barretta, Zheng, and Bertazzi performed the statistical analysis. All authors read and approved the final manuscript.

\section{Acknowledgements}

This work was supported by funding from the NIEHS (R21 ES020010 and R21 ES020984-01). Dr. Baccarelli's laboratory at the Harvard School of Public Health (HSPH) has been supported by the Harvard EPA Center (RD 83479801).

\section{Author details}

${ }^{1}$ Department of Preventive Medicine Feinberg, School of Medicine Northwestern University, 680 North Lake Shore Drive, Suite 1400, Chicago, II 60611, USA. ${ }^{2}$ Robert H. Lurie Comprehensive Cancer Center Feinberg School of Medicine, Northwestern University, Chicago, IL, USA. ${ }^{3}$ Department of Clinical Sciences and Community Health, University of Milan, Milan, Italy. ${ }^{4}$ Epidemiology Unit, Department of Preventive Medicine, Foundation IRCCS Cà Granda Ospedale Maggiore Policlinico, Milan, Italy. ${ }^{5}$ Department of Safety Engineering, China Institute of Industrial Relations, Beijing, China. ${ }^{6}$ Department of Environmental Health, Harvard School of Public Health, Boston, MA, USA. ${ }^{7}$ Department of Occupational Health, SINOPEC Research Institute of Safety Engineering, Qingdao, China. ${ }^{8}$ Department of Occupational and Environmental, Health Peking University Health Science, Center No. 38 Xueyuan Road Haidian District, Beijing 100191, China.

Received: 22 October 2012 Accepted: 12 April 2013

Published: 29 April 2013 


\section{References}

1. Nawrot TS, Torfs R, Fierens F, De Henauw S, Hoet PH, Van Kersschaever G, De Backer G, Nemery B: Stronger associations between daily mortality and fine particulate air pollution in summer than in winter: evidence from a heavily polluted region in western Europe. J Epidemiol Community Health 2007, 61:146-149.

2. Brook RD, Rajagopalan S, Pope CA 3rd, Brook JR, Bhatnagar A, Diez-Roux AV, Holquin F, Hong Y, Luepker RV, Mittleman MA, et al: Particulate matter air pollution and cardiovascular disease: an update to the scientific statement from the American Heart Association. Circulation 2010, 121:2331-2378.

3. Weinmayr G, Romeo E, De Sario M, Weiland SK, Forastiere F: Short-term effects of PM10 and NO2 on respiratory health among children with asthma or asthma-like symptoms: a systematic review and meta-analysis. Environ Health Perspect 2010, 118:449-457.

4. Ling SH, van Eeden SF: Particulate matter air pollution exposure: role in the development and exacerbation of chronic obstructive pulmonary disease. Int I Chron Obstruct Pulmon Dis 2009, 4:233-243.

5. Turner MC, Krewski D, Pope lii CA, Chen Y: Gapstur SM. Thun MJ: Long-Term Ambient Fine Particulate Matter Air Pollution and Lung Cancer in a Large Cohort of Never Smokers. Am J Respir Crit Care Med; 2011.

6. Chen H, Goldberg MS, Villeneuve PJ: A systematic review of the relation between long-term exposure to ambient air pollution and chronic diseases. Rev Environ Health 2008, 23:243-297.

7. Li N, Sioutas C, Cho A, Schmitz D, Misra C, Sempf J, Wang M, Oberley T, Froines J, Nel A: Ultrafine particulate pollutants induce oxidative stress and mitochondrial damage. Environ Health Perspect 2003, 111:455-460.

8. Baccarelli A, Cassano PA, Litonjua A, Park SK, Suh H, Sparrow D, Vokonas P, Schwartz J: Cardiac autonomic dysfunction: effects from particulate air pollution and protection by dietary methyl nutrients and metabolic polymorphisms. Circulation 2008, 117:1802-1809.

9. Lee HC, Wei YH: Mitochondrial role in life and death of the cell. J Biomed Sci 2000, 7:2-15.

10. Gianotti TF, Sookoian S, Dieuzeide G, Garcia SI, Gemma C, Gonzalez CD, Pirola CJ: A decreased mitochondrial DNA content is related to insulin resistance in adolescents. Obesity (Silver Spring) 2008, 16:1591-1595.

11. Wong J, McLennan SV, Molyneaux L, Min D, Twigg SM, Yue DK: Mitochondrial DNA content in peripheral blood monocytes: relationship with age of diabetes onsetand diabetic complications. Diabetologia 2009, 52:1953-1961.

12. Lee HK, Song JH, Shin CS, Park DJ, Park KS, Lee KU, Koh CS: Decreased mitochondrial DNA content in peripheral blood precedes the development of non-insulin-dependent diabetes mellitus. Diabetes Res Clin Pract 1998, 42:161-167.

13. Song J, Oh JY, Sung YA, Pak YK, Park KS, Lee HK: Peripheral blood mitochondrial DNA content is related to insulin sensitivity in offspring of type 2 diabetic patients. Diabetes Care 2001, 24:865-869.

14. Weng SW, Lin TK, Liou CW, Chen SD, Wei YH, Lee HC, Chen IY, Hsieh CJ, Wang PW: Peripheral blood mitochondrial DNA content and dysregulation of glucose metabolism. Diabetes Res Clin Pract 2009, 83:94-99.

15. Kim MY, Lee JW, Kang HC, Kim E, Lee DC: Leukocyte mitochondrial DNA (mtDNA) content is associated with depression in old women. Arch Gerontol Geriatr 2011, 53:e218-221.

16. Varanasi SS, Francis RM, Berger CE, Papiha SS, Datta HK: Mitochondrial DNA deletion associated oxidative stress and severe male osteoporosis. Osteoporos Int 1999, 10:143-149.

17. Guo Y, Yang TL, Liu YZ, Shen H, Lei SF, Yu N, Chen J, Xu T, Cheng Y, Tian Q, et al: Mitochondria-wide association study of common variants in osteoporosis. Ann Hum Genet 2011, 75:569-574.

18. Kim JH, Lee DC: Mitochondrial DNA copy number in peripheral blood is associated with femoral neck bone mineral density in postmenopausal women. J Rheumatol 2012, 39:1465-1472.

19. Xing J, Chen M, Wood CG, Lin J, Spitz MR, Ma J, Amos Cl, Shields PG, Benowitz $\mathrm{NL}$, Gu J, et al: Mitochondrial DNA content: its genetic heritability and association with renal cell carcinoma. J Natl Cancer Inst 2008, 100:1104-1112.

20. Huang CH, Su SL, Hsieh MC, Cheng WL, Chang CC, Wu HL, Kuo CL, Lin TT, Liu CS: Depleted leukocyte mitochondrial DNA copy number in metabolic syndrome. J Atheroscler Thromb 2011, 18:867-873.

21. Shen $M$, Zhang L, Bonner MR, Liu CS, Li G, Vermeulen R, Dosemeci M, Yin S, Lan Q: Association between mitochondrial DNA copy number, blood cell counts, and occupational benzene exposure. Environ $\mathrm{Mol}$ Mutagen 2008, 49:453-457.
22. Carugno M, Pesatori AC, Dioni L, Hoxha M, Bollati V, Albetti B, Byun HM, Bonzini M, Fustinoni S, Cocco P, et al: Increased mitochondrial DNA copy number in occupations associated with low-dose benzene exposure. Environ Health Perspect 2011.

23. Hou L, Zhu ZZ, Zhang X, Nordio F, Bonzini M, Schwartz J, Hoxha M, Dioni L, Marinelli $B$, Pegoraro V, et al: Airborne particulate matter and mitochondrial damage: a cross-sectional study. Environ Health 2010, 9:48.

24. Lynch SM, Weinstein SJ, Virtamo J, Lan Q, Liu CS, Cheng WL, Rothman N, Albanes D, Stolzenberg-Solomon RZ: Mitochondrial DNA copy number and pancreatic cancer in the alpha-tocopherol beta-carotene cancer prevention study. Cancer Prev Res (Phila) 2011, 4:1912-1919.

25. Janssen BG, Munters E, Pieters N, Smeets K, Cox B, Cuypers A, Fierens F, Penders J, Vangronsveld J, Gyselaers W, Nawrot TS: Placental mitochondrial DNA content and particulate air pollution during in utero life. Environ Health Perspect 2012, 120:1346-1352.

26. Bouhours-Nouet N, May-Panloup P, Coutant R, de Casson FB, Descamps P, Douay $O$, Reynier P, Ritz P, Malthiery Y, Simard G: Maternal smoking is associated with mitochondrial DNA depletion and respiratory chain complex III deficiency in placenta. Am J Physiol Endocrinol Metab 2005, 288:E171-177.

27. Bank W: World Development Indicators. 2011.

28. ISO: ISO 9835, Ambient air - Determination of a black smoke index. International Organization for Standardization: Geneva; 1993.

29. Kinney PL, Aggarwal M, Northridge ME, Janssen NA, Shepard P: Airborne concentrations of PM(2.5) and diesel exhaust particles on Harlem sidewalks: a community-based pilot study. Environ Health Perspect 2000, 108:213-218.

30. Janssen NA, van Vliet PH, Aarts F, Harssema H, Brunekree B: Assessment of exposure to traffic related air pollution of children attending schools near motorways. Atmospheric Environment 2001, 35:3875-3884.

31. Reynier P, May-Panloup P, Chretien MF, Morgan CJ, Jean M, Savagner F, Barriere $P$, Malthiery Y: Mitochondrial DNA content affects the fertilizability of human oocytes. Mol Hum Reprod 2001, 7:425-429.

32. Lin CS, Wang LS, Tsai CM, Wei YH: Low copy number and low oxidative damage of mitochondrial DNA are associated with tumor progression in lung cancer tissues after neoadjuvant chemotherapy. Interact Cardiovasc Thorac Surg 2008, 7:954-958.

33. Baccarelli A, Barretta F, Dou C, Zhang X, McCracken JP, Diaz A, Bertazzi PA, Schwartz J, Wang S, Hou L: Effects of particulate air pollution on blood pressure in a highly exposed population in Beijing. China: A repeatedmeasure study. Environ Health 2011, 10:108.

34. Pope CA 3rd, Burnett RT, Krewski D, Jerrett M, Shi Y, Calle EE, Thun MJ: Cardiovascular mortality and exposure to airborne fine particulate matter and cigarette smoke: shape of the exposure-response relationship. Circulation 2009, 120:941-948.

35. Lee $\mathrm{HC}$, Wei YH: Mitochondrial biogenesis and mitochondrial DNA maintenance of mammalian cells under oxidative stress. Int J Biochem Cell Biol 2005, 37:822-834.

36. Ren C, Park SK, Vokonas PS, Sparrow D, Wilker E, Baccarelli A, Suh HH, Tucker KL, Wright RO, Schwartz J: Air pollution and homocysteine: more evidence that oxidative stress-related genes modify effects of particulate air pollution. Epidemiology 2010, 21:198-206.

37. Haden DW, Suliman HB, Carraway MS, Welty-Wolf KE, Ali AS, Shitara H, Yonekawa $\mathrm{H}$, Piantadosi CA: Mitochondrial biogenesis restores oxidative metabolism during Staphylococcus aureus sepsis. Am J Respir Crit Care Med 2007, 176:768-777.

38. Pyle A, Burn DJ, Gordon C, Swan C, Chinnery PF, Baudouin SV: Fall in circulating mononuclear cell mitochondrial DNA content in human sepsis. Intensive Care Med 2010, 36:956-962.

39. Kaaman M, Sparks LM, van Harmelen V, Smith SR, Sjolin E, Dahlman I, Arner P: Strong association between mitochondrial DNA copy number and lipogenesis in human white adipose tissue. Diabetologia 2007, 50:2526-2533.

40. Thyagarajan B, Wang RW, Barcelo H, Koh WP, Yuan JM: Mitochondrial copy number is associated with colorectal cancer risk. Cancer Epidem Biomar 2012, 21:1574-1581.

41. Purdue MP, Hofmann JN, Colt JS, Hoxha M, Ruterbusch JJ, Davis FG, Rothman N, Wacholder S, Schwartz KL, Baccarelli A, Chow WH: A case-control study of peripheral blood mitochondrial DNA copy number and risk of renal cell carcinoma. PLoS One 2012, 7.

42. Collins ML, Eng S, Hoh R, Hellerstein MK: Measurement of mitochondrial DNA synthesis in vivo using a stable isotope-mass spectrometric technique. J Appl Physiol 2003, 94:2203-2211. 
43. Gross NJ, Getz GS, Rabinowitz M: Apparent turnover of mitochondrial deoxyribonucleic acid and mitochondrial phospholipids in the tissues of the rat. J Biol Chem 1969, 244:1552-1562.

44. Clay Montier LL, Deng JJ, Bai Y: Number matters: control of mammalian mitochondrial DNA copy number. J Genet Genomics 2009, 36:125-131.

45. Pillay J, den Braber I, Vrisekoop N, Kwast LM, de Boer RJ, Borghans JA, Tesselaar K, Koenderman L: In vivo labeling with $2 \mathrm{H} 2 \mathrm{O}$ reveals a human neutrophil lifespan of 5.4 days. Blood 2010, 116:625-627.

46. Nurkiewicz TR, Porter DW, Hubbs AF, Stone S, Moseley AM, Cumpston JL, Goodwill AG, Frisbee SJ, Perrotta PL, Brock RW, et al: Pulmonary particulate matter and systemic microvascular dysfunction. Res Rep Health Eff Inst 2011:3-48.

47. Nurkiewicz TR, Porter DW, Barger M, Millecchia L, Rao KM, Marvar PJ, Hubbs AF, Castranova V, Boegehold MA: Systemic microvascular dysfunction and inflammation after pulmonary particulate matter exposure. Environ Health Perspect 2006, 114:412-419.

48. Becker S, Mundandhara S, Devlin RB, Madden M: Regulation of cytokine production in human alveolar macrophages and airway epithelial cells in response to ambient air pollution particles: further mechanistic studies. Toxicol Appl Pharmacol 2005, 207:269-275.

49. Diez Roux AV, Auchincloss AH, Astor B, Barr RG, Cushman M, Dvonch T, Jacobs DR Jr, Kaufman J, Lin X, Samson P: Recent exposure to particulate matter and C-reactive protein concentration in the multi-ethnic study of atherosclerosis. Am J Epidemiol 2006, 164:437-448.

50. Zeger SL, Thomas D, Dominici F, Samet JM, Schwartz J, Dockery D, Cohen A: Exposure measurement error in time-series studies of air pollution: concepts and consequences. Environ Health Perspect 2000, 108:419-426.

51. Wilson WE, Brauer M: Estimation of ambient and non-ambient components of particulate matter exposure from a personal monitoring panel study. J Expo Sci Environ Epidemiol 2006, 16:264-274.

52. Avery CL, Mills KT, Williams R, McGraw KA, Poole C, Smith RL, Whitsel EA: Estimating error in using ambient PM2.5 concentrations as proxies for personal exposures: a review. Epidemiology 2010, 21:215-223.

\section{doi:10.1186/1743-8977-10-17}

Cite this article as: Hou et al:: Inhalable particulate matter and mitochondrial DNA copy number in highly exposed individuals in Beijing, China: a repeated-measure study. Particle and Fibre Toxicology 2013 10:17.

\section{Submit your next manuscript to BioMed Central and take full advantage of:}

- Convenient online submission

- Thorough peer review

- No space constraints or color figure charges

- Immediate publication on acceptance

- Inclusion in PubMed, CAS, Scopus and Google Scholar

- Research which is freely available for redistribution 